\title{
Concomitant Use Of L-arginine With High Butter And Corn Oil Diet Prevent Their Harmful Effects On Adrenocortical Cells Of Albino Rats
}

Iram Quddus, Farhana Samir, Humera Waqar, Sarwer Qureshi

ABSTRACT:

Objective: To compare the bichemical and morphological effects of L-Arginine against the changes caused by butter and corn oil supplementation

Study design: A prospective experimental study

Place: Department of Anatomy BMSI, JPMC

Duration: August to October 2008.

Methodology:Male Albino rats weighing 200 - 240gm were selected and divided into 5 groups. Group 'CL' received standard laboratory diet. Group 'Bu' received 20\% added unsalted butter in diet. Group 'Co' received 20\% added corn oil in diet. Group 'BuAr' received 20\% Butter with L-Arginine 300mg / kg body weight / day orally .Group'CoAr' received $20 \%$ corn oil along with L-Arginine $300 \mathrm{mg} / \mathrm{kg}$ body weight/ day orally. On completion of study period that is 4 weeks, animals were sacrifised. Blood was drawn for hormonal assays. Adrenal glands were removed and fixed in buffered neutral formalin. Right adrenals were processed and sectioned at4 $\mu \mathrm{m}$ thickness to be stained with Mallory trichrome stain to visualize blood vessel. Left adrenalswere sectioned with cryostat in 10um sections and stained with Oil red $\mathrm{O}$ to visualize fat in cells.

Results:Highly significant and moderately significant decrease observed in ACTH (Adrenocorticotrophic hormone)levels in Group BuArand CoAr when compared to Bu and Co respectively; insignificant difference was found between BuAr\&CoAr. Moderately significant and significant decrease observed in corticosterone levels in Group BuAr and CoAr when compared to Buand Co respectively. Insignificant difference was found between BuAr and CoAr . Mallory trichrome stained section showed less dilated blood vessels in BuAr\&CoAr compared to Bu \& Co respectively, while difference among the former two was not remarkable. Oil red O stained sections showed less densely packed fat globules in group BuAr\&CoAr compared to Bu and $\mathbf{C o}$ respectively. Difference between BuAr\&CoAr was not marked.

Conclusion: Butter has more stimulatory effect on adrenal cortical cells but the comparison with corn oil is not statistically significant except for ACTH levels. L Arginine seems to be effective in lowering the levels of stress hormones, fat accumulation and vasodilatation when given along with corn oil and butter oil.

Key words: Adrenal gland, Butter, Corn oil, L-arginine.

\section{INTRODUCTION:}

In Pakistan the second ranking source of calories is edible oil $^{1}$. Butter and butter oil (Desi ghee which is formed by heating butter and removing solids) were more comonly used raw and for cooking food. Share of butter oil in total consumable oil dropped drastically from 58\% in 1972 to about $3.8 \%$ in 1990. Different types of vegetable oils and

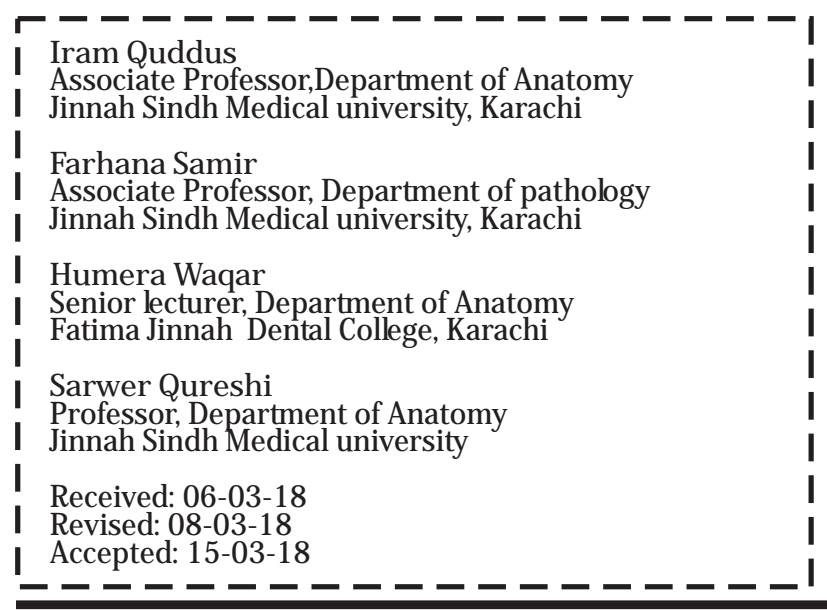

vanaspati ghee (hydrogenated vegetable oil) gradually replaced butter and butter oil due to various reason; one among them being the increased awareness of health benefits of vegetable oils (polyunsaturated fat proportion). Among these oils, corn oil and soybean took the lead ${ }^{2}$. Beneficial effects of corn and soybean oil are over emphasized that these oils used in whatever quantity are totally safe ${ }^{3}$. Butter despite of claims of being hazardous to cardiovascular system is a good source of natural vitamin $\mathrm{D}, \mathrm{A}$ and calcium. The synthetic vitamins added in different oils are by no means a match to natural vitamins ${ }^{4}$. Fat in excess whether in form of butter, lard or vegetable oil has adverse effects on whole body, but it affects each system and organ in different way ${ }^{5}$.

Fat acts as a substrate for steroidogenesis in adrenal gland which belongs to body's stress system that is Hypothalamo -pituitary- adrenal axis (HPA axis), captures attention because of its involvement in the pandemics of metabolic syndrome which ends up in type 2 diabetes and coronary heart disease ${ }^{6}$.The proposed mechanism underlying increased steroidogenesis in response to fatty foods is 
adrenal hyperplasia and hypertrophy by increased expression of multiple genes involved. One among these was elevated sonic hedgehog signaling, as a result of obesity due to fatty diet in Gli 1 - positive progenitor cells which give rise to steroidogenic cells and thus increased hormone levels ${ }^{7}$.

$\mathrm{L}$ arginine which is a known negative modulator of steroidogenesis by nitric oxide formation, is normally present in body and considered semi- essential amino $\mathrm{acid}^{8}$. Supplementation of L -Arginine has been done for many other form of stress or sand in other systems of body ${ }^{9}$.

Present study compares the effectiveness of L Arginine in attempting to maintain the normal morphology and function of adrenal gland when excess of two different types of commonly used fatty diet were given.

\section{METHODOLOGY:}

This study was conducted in the department of Anatomy, BMSI, JPMC from August to October 2008. The study sample included 25 male adult Albino rats aged around 90-120 days ,weighing 200-240gm .They were kept on standard laboratory diet for a week for observation, with 12 hours dark and light cycle, before commencement of study period. Animals were divided into five groups according to the diet they received, each comprising of 5 animals. Group 'CL' received normal laboratory diet. Group 'Bu' received $20 \mathrm{gm}$ unsalted dairy butter in $100 \mathrm{gm}$ of diet representing saturated fat. Group 'Co' received20 $\mathrm{ml}$ corn oil in $100 \mathrm{gm}$ of diet as unsaturated fat. Group 'BuAr' received Butter along with 300mg L-Arginine / $\mathrm{kg}$ body weight/ day orally (General Nutrition Corporation, Pittsburg, USA) .Group 'CoAr' received Corn oil along with 300mg L-Arginine / kg body weight .Animals were housed in cages under standard laboratory conditions of 12 hours day and night cycle. After completion of 4 weekstudy period animals were dissected after giving ether anesthesia. Blood samples were taken at the time of dissection through intra-cardiac puncture. Each sample (4ml) shifted to lavender tube containing EDTA and centrifuged for 15 minutes at $3500 \mathrm{~Hz}$ to get plasma, which was stored at $-20^{\circ} \mathrm{C}$ for analysis. Plasma ACTH (Adrenocorticotrophic hormone) and Corticosterone levels were determined by Elisa method Adrenals were removed and fixed in $10 \%$ buffered neutral formalin for 24 hours. Right adrenals were processed in ascending grades of Alcohol and were cleared with Xylene and infiltered in paraffin to be sectioned at $4 \mu \mathrm{m}$ thickness. The sections were then stained with Mallory trichrome stain to observe the blood vessels. Left adrenals after fixation in $10 \%$ buffered neutral formalin were sectioned by cryostat to $10 \mu \mathrm{m}$ sized sections which were stained with Oil Red O to demonstrate lipids in cell. Statistical analysis was done by students ' $t$ ' test and $P$ value less than
0.05 was considered as significant. Calculations were done by utilizing computer software SPSS version 13 .

\section{RESULTS:}

Highly significant $(\mathrm{P}<0.001)$ increase found when values of ACTH hormone of $\mathbf{B u}$ and $\mathbf{C o}$ groups were compared with $\mathbf{C l}$. Highly significant $(\mathrm{P}<0.001$ ) and moderately significant $(\mathrm{P}<0.01)$ decrease observed in group BuAr and $\mathbf{C o A r}$ when compared to $\mathbf{B u}$ and $\mathbf{C o}$ respectively. Insignificant ( $\mathrm{P}>0.05)$ difference was found when $\mathbf{B u A r}$ and CoAr groups were compared with each other. (Fig,1)

Significant $(\mathrm{P}<0.05)$ and insignificant $(\mathrm{P}>0.05)$ differences were seen in plasma Corticosterone levels of group Bu and $\mathbf{C o}$ when compared to $\mathbf{C L}$. Moderately significant $(\mathrm{P}<0.01)$ and significant $(\mathrm{P}<0.05)$ decrease in corticosterone levels were observed in BuAr and $\mathbf{C o A r}$ when compared to $\mathbf{B u}$ and $\mathbf{C o}$, while insignificant $(\mathrm{P}>0.05)$ difference was seen in levels among BuAr and CoAr. (Fig,2)

In Mallory trichrome stained sections of adrenal cortices of $\mathbf{B u}$ and $\mathbf{C o}$ groups increased number of dilated blood vessels were seen when compared with CL group. In sections of BuAr and CoAr less numerous and less dilated blood vessels were seen compared to $\mathbf{B u}$ and $\mathbf{C o}$ respectively. (Fig, 3 and 4). Comparison of the sections from group BuAr and CoAr did not show any marked difference.

Sections of adrenal cortices of group Bu and $\mathbf{C o}$ stained with Oil red O stain showed more densely packed and densely packed fat globules respectively when compared to $\mathbf{C L}$ group. Less densely packed globules were seen in both BuAr and CoAr groups when compared to Bu and Co groups respectively. (Fig, 5 and 6) Comparison of BuAr and CoAr did not show much difference.

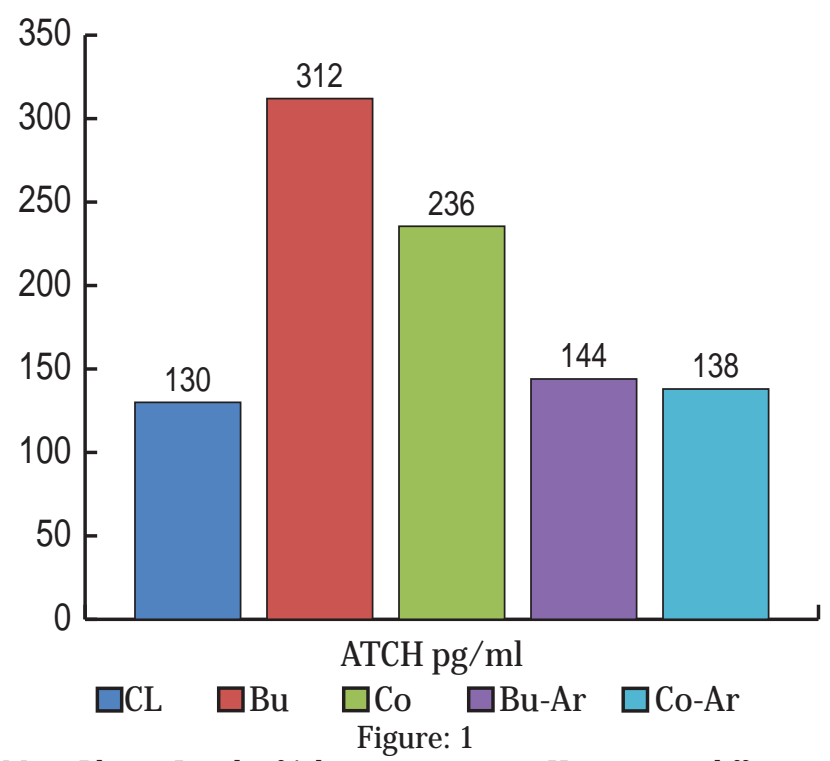

Mean Plasma Levels of Adrenocorticotropic Hormone in different groups of albino rats 


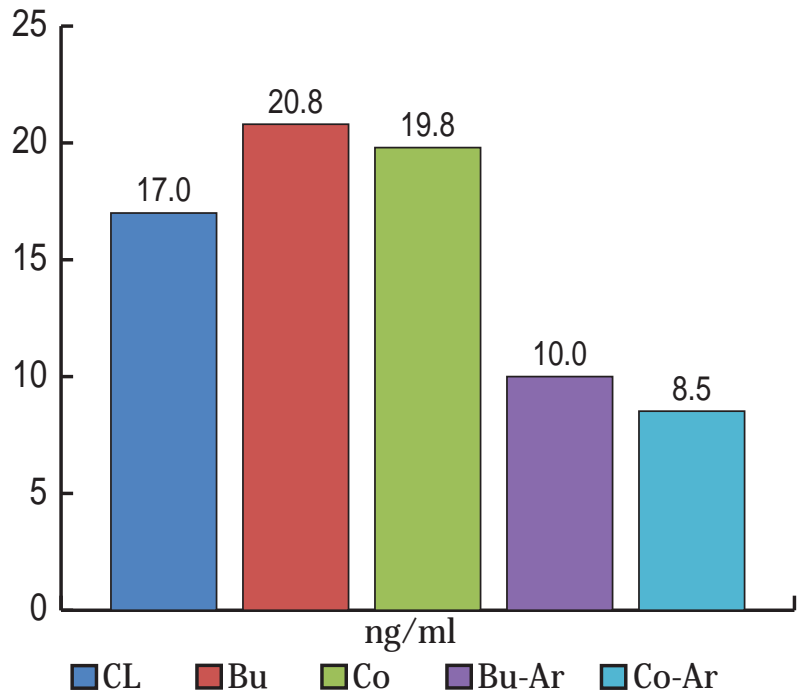

Figure: 2

Mean Plasma Levels of Corticosterone in different groups of albino rats

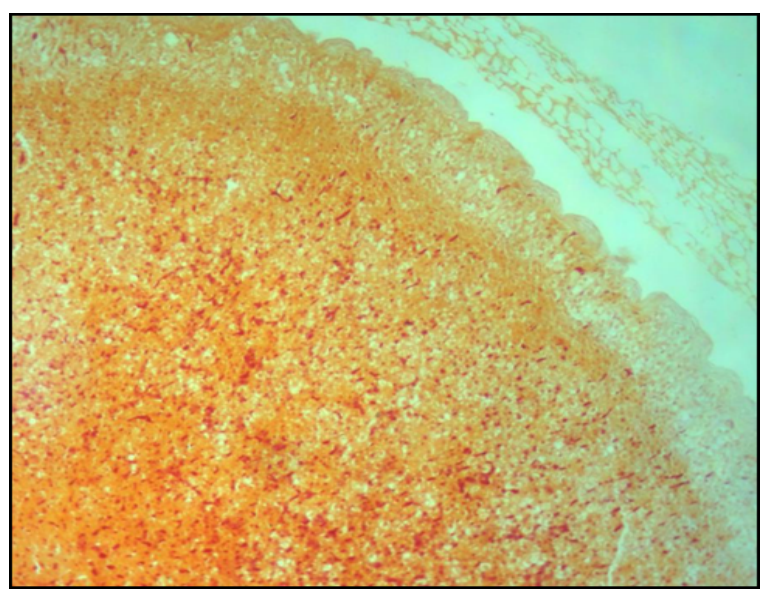

Figure-3

Mallory trichrome stained $4 \mu \mathrm{m}$ thick sections of rat adrenal cortex showing less dilated blood vessels after 4 weeks treatment with Butter and L-Arginine. (X 100)

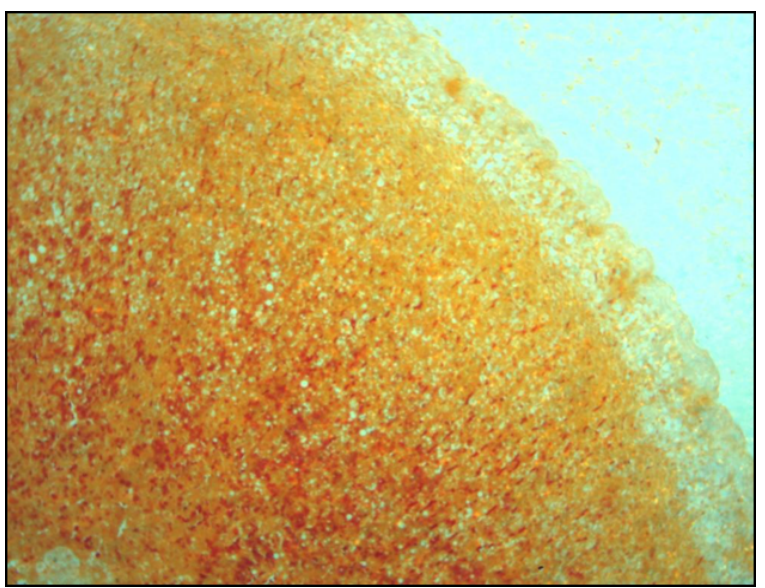

Figure- 4

Mallory trichrome stained 4 um thick sections of rat adrenal cortex showing less dilated blood vessels after 4 weeks treatment with Corn oil and L-Arginine. (X 100)

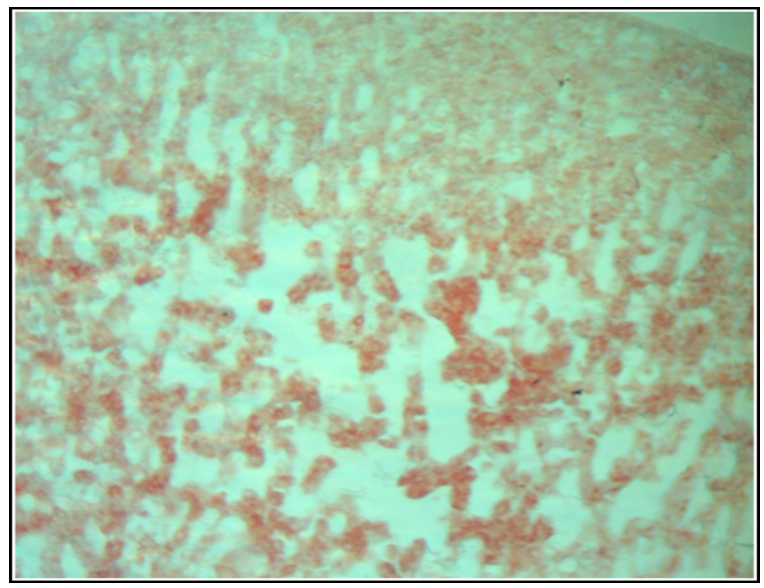

Figure-5

Oil red $\mathrm{O}$ and Hematoxylin stained ,10 $\mu \mathrm{m}$ thick frozen sections of rat adrenal cortex showing less densely packed distribution of fat globules after 4 weeks treatment with Butter and LArginine. (X 100)

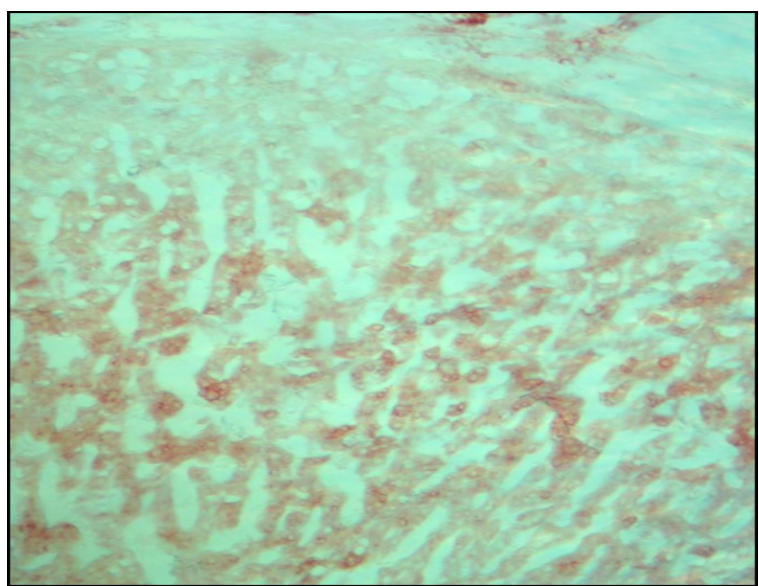

Figure- 6

Oil red $\mathrm{O}$ and Hematoxylin stained ,10 $10 \mathrm{~m}$ thick frozen sections of rat adrenal cortex showing less densely packed distribution of fat globules after 4 weeks treatment with Corn oil and LArginine. (X 100)

\section{DISCUSSION:}

Debate on saturated and unsaturated fat sources in diet has been going for many years, the comparison mostly is done in relation to blood levels of LDLs ,HDLs , cholesterol and triglycerides ; coronary artery disease and liver accumulation. Effects of excessive fat consumption on other organs with different types of fat are comparatively less studied.

Present study compared Butter and corn oil effects on adrenal while Manna et $\mathrm{al}^{10}$ compared the effects of ustard oil and Ghee on serum lipids. Sharmaet al ${ }^{11}$ observed no effect with $10 \%$ Ghee on serum cholesterol in fischer inbred rats. Mohammadi and Aziz ${ }^{12}$ found increased expression of Apo lipoprotein B in intestine with cow derived Ghee. Nirmalaet al ${ }^{13}$ observed that serum cholesterol levels were lowered with $5 \%$ cured Ghee(made by cultured butter) compared to cream ghee (clarified butter). Silvaet al ${ }^{14}$ used butter with sugar to produce 
obesity under controlled temperature and that elevated the serum lipids also.

Results of hormonal essays clearly depict triggering effect of both butter and corn oil on secretion of ACTH and corticosterone. Both corn oil and butter treated groups showed highly significant increase in ACTH levels .Birem ${ }^{15}$ et al found $202 \%$ higher levels of ACTH in palm olive receiving animals compared to control in study of 7 months , they found a positive correlation between ACTH levels and HDL - cholesterol. Another study ${ }^{16}$ (EL-Feky etal, 2010) also observed that fat which enter the adrenal gland causes increase in lipid rich cells in zona fasciculata and reticularis. L Arginine used along with butter and corn oil was able to decrease the levels of ACTH but the difference was not significant among the two types of fat. Mahar ${ }^{17}$ et al found L Arginine effective in lowering the raised stress hormone levels induced by streptozotocin.

Corticosterone levels are direct indicators of stress level in body. Any agent which cause a decrease in its level is actually decreasing the stress on the body. Although corn oil seems to have less stressful effects as the levels of corticosterone indicates in present study, but its comparison with butter showed insignificant difference. Swierczynskaet $\mathrm{al}^{7}$ also observed increased levels of corticosterone in response to high fat feeding. Liu et $\mathrm{al}^{6}$ found increased corticosterone levels after giving 19.4\% added fat in diet. L-arginine presumably prevented excessive increase in corticosterone level triggered by both butter and corn oil by nitric oxide formation. L arginine has been used to decrease the cortisol levels in chronic stress in turbots by Costas and his fellows ${ }^{9}$. Diazet al observed inhibitory effect of vitamin C on adrenal gland with down regulation of steroidogenesis, which was given to prevent obesity ${ }^{18}$.

Mallory stained sections of butter and corn oil with L Arginine showed reduction in dilatation of blood vessels which was caused by both edible oils. Milovanovic et $\mathrm{al}^{19}$ found increased size of capillaries and hyperemia in Azan stained sections of adrenal gland exposed to acute ethanol damage. While Saleh and Demerdash discovered during their study that $\mathrm{L}$ arginine ameliorates the vascular changes in kidney cortex caused by cisplatin ${ }^{20}$. Saad et al. also augmented that L-arginine significantly attenuated the oxidative stress and nephrotoxic effect of carbon tetrachloride induced renal toxicity ${ }^{21}$.

Mansour et al. observed that oral administration of Larginine before cyclosporine (CsA) injection produced a significant protection against nephrotoxity induced by CsA. ${ }^{22}$ Fat which is a substrate for steroidogenesis can be seen in excessive amount in both butter and corn oil group sections stained with Oil red O stain. L- arginine caused decreased accumulation in both butter and corn oil groups by formation of nitric oxide as mentioned earlier ${ }^{8}$.

Email et al. also observed localized effects of steroidogenesis and NO synthesis from L-arginine. on liver sinusoids in AZA-treated mice ${ }^{23}$.Nitric oxide is important for the modulation of vascular tone, inflammation, immune function, endothelial function ${ }^{24}$. Vitamin $\mathrm{C}$ was used by Campion et $\mathrm{al}^{25}$ who found that vitamin $\mathrm{C}$ down regulates steroidogenic genes in adrenal gland.

\section{CONCLUSION:}

When comparing the effects of butter and corn oil and the prevention by L Arginine on hormonal levels and histological findings, it is obvious that L Arginine prevents the fat induced changes but statistically insignificant difference was present in the protection provided by Larginine, the mechanism is still to be explored. Both types of fat in excess appears to be harmful.

\section{REFERENCE:}

1. Malik SJ ,Nazli H ,Shahzad A ,Mehmood A . Food Consumption Patterns and Nutrition . Pakistan strategy support program 2015.

2. Haq R .Estimating Demand and Supply of Edible Oil in Pakistan. Pakistan J. Agric. Soc. Sci. 1993; 7( 2)

3. Joseph M. 8 Harmful Effects of Soybean Oil: What It Really Does to You. 10 2017. https:/ / nutritionadvance.com / harmful-effects-of-soybean-oil .Retrieved on 3rd March 2018

4. SchmidA ,Walther B . Natural vitamin D Content in animal products.AdvNutr. 2013 ; 4(4): 453-462.

5. 5.Buettner R, Parhofer KG, Woenckhaus M, Wrede CE, Kunz-Schughart LA,Schölmerich J, et al.Defining high-fatdiet rat models: metabolic and molecular effects of different fat types.J MolEndocrinol 2006;36:485-50

6. Liu L,junqiangYangJ , Qian F, lu C.Hypothalamic-pituitaryadrenal axis hypersensitivity in female rats on a postweaning high-fat diet after chronic mild stress Experimental and therapeutic medicine 2017;14:439-446

7. Swierczynska MM, Mateska I, Peitzsch M, Bornstein SR, Chavakis T, Eisenhofer G et al Changes in morphology and function of adrenal cortex in mice fed a high-fat diet. Int J Obes2015 Feb;39(2):321-30. .

8. Repetto EM, Pannunzio V, Astort F, Calejman C, Moreno $\mathrm{MB}$, PignataroOP. Characterization of L-arginine transport in adrenal cells: effect of ACTH. Am J PhysiolEndocrinolMetab. 2006 ;291(2): 291-7.

9. Costas B, Rego P, Conceicao L, Dias J ,Afonso A. Dietary arginine supplementation decreases plasma cortisol levels and modulates immune mechanisms in chronically stressed turbot (Scophthalmusmaximus). Aquaculture Nutrition 2013 ; 19(1): 25-38.

10. Manna S, Sharma HB , Vyas S, Kumar J. Comparison of Mustard Oil and Ghee Consumption on the History of Coronary Heart Disease in Urban Population of India.J ClinDiagn Res 2016; 10(10):1-5

11. Sharma $H$, Zhang X, DwivediC.The effect of ghee (clarified 
butter) on serum lipid levels and microsomal lipid peroxidation. Ayu. 2010; 31(2): 134-140.

12. Mohammadi G, Azizi H. Effect of corn oil, olive oil and sheep's and cow's ghee on the expression of apoB protein. International Journal of Medical Laboratory 2015;2(1):4149.

13. Nirmala K S ,Manjula S, Sahajananda H. Effect of two types of dietary ghee on serum lipid levels in rats .J. Evolution Med. Dent. Sci2016 ; 5 (49) : 3240-44

14. Silva C, Perris PD, Fernandez I, Godoy MF, Mambrin C, Slobodianik NH, et al. Effectsof high-fat diets from different sources on serum and thymus lipid profile: study in an experimental model.EndocrMetab Immune Disord Drug Targets. 2014;14(2):77-83.

15. Birem Z, Tabani K, Lahfa F, Djaziri R ,Hadjbekkouche F, Koceir EA. Effects of colocynth alkaloids and glycosides on Wistar rats fed high-fat diet. A biochemical and morphological study.Folia histochemica et cytobiologica 2017;55(2): 74-85

16. El-feky $\mathrm{H}$, Adelsalah, Youssef $\mathrm{H}$ and Mohammed S. Histological study of the effects of induced diabetes on zona glomerulosa of the adrenal cortex of adult male albino rat. Egypt J Histol, March 2010, Vol 33, No. 1, 17-22.

17. MaharY, Shoro AA, Naqvi A. The effect of l-Arginine and Insulin on Histological Changes in Sreptozotocintreated Rat Adrenal Gland .P J M H S 2012; 6(4): 843-6.

18. Garcia-Diaz DF, Opez-Legarrea P, Quintero P, Martinez JA. Vitamin Cin the treatment and/ or prevention of obesity. J NutrSciVitaminol 2014 ; 60: 367-379
19. MilovanoviæT, Budec M, Balint-Periæ L, Koko V, Todoroviæ V.Effects of acute administration of ethanol on the rat adrenal cortex.tud Alcohol. 2003 ;64(5):662-8.

20. Saleh S, El-Demerdash E. Protective Effects of L-Arginine against Cisplatin-Induced Renal Oxidative Stress and Toxicity: Role of Nitric Oxide .Clinical Pharmacology \& Toxicology 2005; 97: 91-97.

21. Saad EA. Kidney response to L-arginine treatment of carbon tetrachloride-induced hepatic injury in mice. Natural Science. 2013;5(01):1-6.http:/ / dx.doi.org/ 10.4236/ns.2013.51001

22. Mansour, M., Daba, M.H., Gado, A., Al-Rjkabi, A. and AlMajed, A. Protective effect of L-arginine against nephrotoxicity induced by cyclosporine in normal rats. Pharmacological Research.2002.45; 441-46.

23. Amal M. Moustafa and Faried A. Impact of L-arginine on Azathioprine-Induced Chronic Hepatotoxicity in Mice: Biochemical and Ultrastructural Study; Egypt. J. Histol. 2010; 33(3): 407 - 18

24. Novaes M, Lima L, Novaes L and Souza M. : Metabolic and hematological effects of dietary supplementation with arginine on rats bearing ascitic walker 256 tumor. Ann.Nutr. Metab.2004; 48(6): 404-408.

25. Campion J, Milagro FI, Fernández D, Martínez JA. Vitamin C supplementation influences body fat mass and steroidogenesis-related genes when fed a high-fat diet.Int J VitamNutr Res. 2008 ;78(2): 87-95. 